\title{
A Razão d'A Nova Ciência das Organizações
}

\section{The Reason in The New Science of Organizations}

\author{
Ariston Azevedo ${ }^{1}$ \\ Universidade Federal do Rio Grande do Sul / Escola de Administração, Porto Alegre - RS, Brasil \\ Renata Ovenhausen Albernaz ${ }^{2}$ \\ Universidade Federal do Rio Grande do Sul / Escola de Administração, Porto Alegre - RS, Brasil
}

Em homenagem a Wilson Pizza Júnior e
Francisco Gabriel Heidemann

\section{Resumo}

Neste trabalho, propomos uma interpretação sobre o termo razão para Guerreiro Ramos, particularmente em seu último livro, A nova ciência das organizações. A partir dessa reflexão, temos a intenção de esclarecer aspectos que não foram devidamente aclarados por ele e, assim, oferecer uma linha compreensiva de suas ideias.

Palavras-chave: Redução sociológica. Razão. Racionalidade. Guerreiro Ramos.

\begin{abstract}
In this paper, we propose an interpretation of the term reason according to Guerreiro Ramos, particularly in his latest book, The new science of organizations. Through this reflection, we intend to clarify some aspects he has not made properly clear, thus providing an interpretive approach to his ideas.
\end{abstract}

Keywords: Sociological reduction. Reason. Rationality. Guerreiro Ramos.

I

A intuição e elaboração do conceito de redução sociológica foi ponto marcante do conjunto da obra de Guerreiro Ramos. Embora se perceba lampejos dessa intuição em seus escritos do início dos anos 1940 sobre a literatura latino-americana ${ }^{3}$, sua articulação em caráter mais sistematizado se daria entre os anos de 1954 a 1958, quando viria à tona seu livro de título $A$ redução sociológica: introdução ao estudo da razão sociológica, atualmente considerado um clássico da sociologia brasileira. Nesse livro, porém, a redução sociológica não foi apresentada em sua versão acabada, mas em delineação inicial, no caso, $(i)$ como método

Artigo submetido em 26 de janeiro de 2015 e aceito para publicação em 13 de julho de 2015.

DOI: http://dx.doi.org/10.1590/1679-395152993

1 Doutor em Sociologia Política pela Universidade Federal de Santa Catarina (UFSC); Professor adjunto na UFRGS. Endereço: Rua Washington Luiz, 855 - sala 434 - Centro, CEP 90010-460, Porto Alegre - RS, Brasil. E-mail: ariston.azevedo@ufrgs.br

${ }^{2}$ Doutora em Direito pela Universidade Federal de Santa Catarina (UFSC); Professora adjunta na UFRGS. Endereço: Rua Washington Luiz, 855, Centro, CEP 90010-460, Porto Alegre - RS, Brasil. E-mail: renata.albernaz@terra.com.br

${ }^{3}$ Vide, a esse respeito, texto de nossa autoria, intitulado $A$ redução sociológica em status nascendi: os estudos literários de Guerreiro Ramos publicados na revista Cultura Política (AZEVEDO e ALBERNAZ, 2010). 
de "análise de concepções e de fatos sociais" (GUERREIRO RAMOS, 1965 [1958], p. 53), ou mais precisamente, como "método de assimilação crítica da produção sociológica estrangeira" (GUERREIRO RAMOS, 1965 [1958], p. 16). Tratava-se da proposta de um método combativo, diante de uma constatação fundante, já exposta em seu livro Introdução crítica à sociologia brasileira, de 1957, que a sociologia, no Brasil e em países latino-americanos semelhantemente colonizados, evoluiu sob forte influência de teorias exógenas, que tendo sido dogmatizadas por intelectuais locais, fizeram da sociologia uma ciência de empréstimos, um tipo de saber alienado e alienador, portanto obstáculo epistemológico ao projeto de um "pensamento científico autêntico", nacionalista, consequentemente comprometido com os respectivos projetos de desenvolvimento desses países (GUERREIRO RAMOS, 1957, p. 19).

Nesse sentido, o método da redução sociológica foi elaborado para combater a síndrome alienante que acometia o pensamento sociológico acadêmico brasileiro, mais exatamente uma vertente da tradição sociológica brasileira por ele denominada consular ou enlatada, e contra a qual sempre manifestou opinião depreciativa ${ }^{4}$. Basicamente, essa síndrome se caracterizava pela presença de seis defeitos, em seu entendimento, próprios da "fase infantil" em que se encontrava a sociologia no Brasil, fase tipicamente marcada pelo colonialismo das mentalidades intelectuais. O primeiro deles era o de simetria e sincretismo, que assinalava o fato de o sociólogo brasileiro estar sempre disposto a acolher, em tonalidade mimética, a produção intelectual dos centros europeus e norte-americanos, sem adotar qualquer atitude crítica à mesma, $\mathrm{e}$, ainda mais agravante, a conciliar, doutrinalmente, as mais diversas correntes de pensamento ou teorias produzidas no exterior. O dogmatismo denuncia a postura submissa e apologética percebida na tradição consular, dado que seus representantes tinham por praxe adotar e generalizar os argumentos proferidos por autoridades reconhecidas ou grandes nomes da disciplina sociológica no exterior, de dois modos característicos: na fala ou no discurso sociológico, principalmente pela montagem mecanizada de textos "científicos", e na análise factual da realidade, já viciada de partida.

Uma decorrência direta do dogmatismo era o dedutivismo característico da atitude científica enlatada. Uma vez que às ideias estrangeiras a sociologia consular atribuía valor absoluto de verdade, a tendência era sempre tomá-las como o ponto de partida no processo de compreensão ou explicação dos fatos da vida social brasileira. Dedutivista, portanto, seria aquele sociólogo que desconsiderava as contingências históricas das nações e suas peculiaridades em termos de constituição histórica, uma vez que sua preocupação maior estava em realizar o sincronismo mecânico entre diferentes realidades nacionais.

Os dois últimos defeitos dessa síndrome seriam a alienação e a inautenticidade. A alienação era fruto da condição desplantada ou contemplativa que, via de regra, o sociólogo nacional assumia frente à sua realidade imediata. Para Guerreiro Ramos, essa atitude explicava o fato de o conhecimento sociológico produzido até aquele momento não ser "fruto de esforços tendentes a promover a autodeterminação" e o desenvolvimento da nação brasileira, ou seja, explicava o fato de seu descompromisso social (GUERREIRO RAMOS, 1957, p. 22). Já a inautenticidade seria o resultado de todas as características acima, pois punha à mostra a ficção que era a sociologia produzida no Brasil, uma vez que o "trabalho sociológico" brasileiro não se firmava em “genuínas experiências cognitivas” do sociólogo (GUERREIRO RAMOS, 1957, p. 23).

Mesmo que a finalidade imediata da redução sociológica como método tenha sido a de combater essa síndrome de alienação que acometia a sociologia brasileira, o fato é que a edição de 1958 de $A$ redução sociológica, devido ao envolvimento do autor com diversas outras atividades e questões pessoais, entre elas

\footnotetext{
${ }^{4}$ A diferenciação entre um tipo de sociologia e outro foi assim exposta pelo autor: "há, hoje, no Brasil, duas sociologias: uma enlatada, que se faz, via de regra, nos quadros escolares e no âmbito confinado de reuniões e entidades particularistas de caráter acadêmico; e outra que se exprime predominantemente em comportamentos e que se pensa, por assim dizer, com as mãos, no exercício de atividades executivas e de aconselhamento nos quadros dos negócios privados e governamentais. A primeira, em larga escala, tem sido uma percepção ilusória da realidade do país; a segunda, espécie de crisálida, emerge da vida comunitária nacional e se encaminha no sentido de tornar-se uma autoconsciência das leis particulares da sociedade brasileira" (GUERREIRO RAMOS, 1957, p. 120). Nos anos 1950, os principais representantes da sociologia enlatada estavam vinculados à Universidade de São Paulo (USP), cujo expoente máximo seria o também sociólogo Florestan Fernandes.
} 
seus atritos pessoais dentro e fora do Instituto Superior de Estudos Brasileiros (Iseb), não retratava o projeto por ele originalmente pensado, sendo somente a concretização incipiente de suas proposituras ou, como ele mesmo disse, um "esboço" metodológico. Na verdade, o anseio por elaborar um método que pudesse auxiliar os sociólogos no processo de compreensão da realidade brasileira à luz de sua própria razão sociológica de ser sócio-histórico, e que os possibilitasse assumir uma postura crítico-assimilativa frente a todas as formas de conhecimento e de experiências elaboradas a partir de outras realidades, o fez desenvolver, naquele livro, apenas um dos sentidos do conceito redução sociológica. Foi necessária uma segunda edição, esta publicada em 1965, para que outros dois sentidos do termo fossem explicitados. No prefácio ${ }^{6}$ dessa segunda edição, em meio ao contexto de respostas aos críticos do livro em sua primeira versão, em especial às críticas que lhes foram feitas por Florestan Fernandes e Jacob Gorender ${ }^{7}$, o autor acrescentou à noção de redução sociológica como método duas outras, estas já inspiradas em diferentes linhas de combate, mas ainda convergentes com sua luta contra a alienação.

A noção de redução sociológica (ii) como atitude parentética foi primeiramente apresentada em seu livro Mito e verdade da revolução brasileira, de 1963, no contexto de sua militância política partidária no Partido Trabalhista Brasileiro (PTB) e seu histórico embate político contra o Partido Comunista Brasileiro (PCB) e a ideologia marxista-leninista que este apregoava. Aliás, em matéria de política, Guerreiro Ramos acreditava ser perseguido tanto pela ala da direita quanto pela ala da esquerda. Quando no exercício do mandato de deputado federal pelo estado da Guanabara, destacou essa questão diversas vezes em seus pronunciamentos (p. ex., DCN, 1963c. p. 9677-9678), sempre condenando o servilismo da esquerda e o entreguismo da direita (DCN, 1963a; 1963b) ${ }^{8}$. Certa feita, afirmou que a vida política brasileira vinha sendo conduzida por "lideranças teleguiadas" a "dois falsos dilemas: de um lado, uma pequena direita lúcida de [Ivan] Hasslocher, de [Carlos] Lacerda, de homens que querem fazer deste País um país de ianques de segunda mão, e do outro lado, uma esquerda extremada, de ledores de vulgatas soviéticas, cubanas e chinesas, que querem fazer deste País um país de cubanos, de russos, de chineses de segunda mão" (DCN, 1963a). Assim, segundo ele, somente um "movimento de saneamento ideológico" poderia fazer efeito contra a lesão psíquica provocada pela falsidade ideológica a que se estava exposto; somente uma medida desse caráter para "restituir o processo brasileiro aos seus devidos termos, porque a vida brasileira não pode continuar a ficar subordinada a posições teleguiadas de direita ou esquerda e tem que seguir seu curso normal" (DCN, 1963a).

No livro de 1963, a fim de apontar e desqualificar o dogmatismo dos "esquerdeiros" brasileiros, Guerreiro Ramos buscou inspiração na obra $O$ rinoceronte, de Eugéne Ionesco, na Teoria das elites, de Robert Michels, e na corrente revisionista do marxismo, principalmente em Rosa Luxemburgo e Karl Kautsky. Além disso, com o intuito de denunciar o domínio cognitivo alienante que o PCB sobrepunha às

${ }^{5}$ Como apontado acima, "introdução ao estudo da razão sociológica" era originalmente o subtítulo do livro A redução sociológica, em 1958 e em 1965, primeira e segunda edição, respectivamente, o qual, infelizmente, foi suprimido quando da publicação da terceira edição deste, em 1995. Conceitualmente falando, a razão sociológica pode ser entendida como uma "referência básica, a partir da qual tudo o que acontece em determinado momento de uma sociedade adquire o seu exato sentido" (GUERREIRO RAMOS, 1965, p. 138). É a ela, portanto, que o cientista social deveria estar atento para fins interpretativos dos fatos e acontecimentos sociais. Dito isso, três observações merecem ser feitas: primeira, é que do ponto de vista da historiografia de seus escritos, o termo razão sociológica foi empregado, pela primeira vez, em 1946, no artigo A revolução coperniana da sociologia (GUERREIRO RAMOS, 1946), e sua inspiração está associada ao nome de Gilberto Freyre; segunda, a precisão conceitual que o autor conferiu ao termo em 1958 guarda paralelismos com as ideias de razão histórica de Dilthey e de razão vital de Ortega y Gasset, conforme o mesmo fez questão de ressaltar quando abordou a "lei das fases"; e, terceira, há que se destacar a singularidade que, posteriormente, e como se procurará demonstrar mais à frente neste artigo, o termo razão receberá nos escritos do autor.

${ }^{6}$ Embora a segunda edição do livro tenha sido publicada em 1965, o prefácio data de 1963, ou seja, foi redigido concomitantemente ao seu livro mais árduo, Mito e verdade da revolução brasileira, que é considerado por alguns como o estopim do motivo da cassação de seus direitos políticos, que ocorreu via o Ato Institucional oㅜ 1 (Al1), Ato Complementar 끄 4, de 13 de abril de 1964.

7 As contendas em que se envolveu Guerreiro Ramos tem sido objeto de investigação no bojo dos estudos sobre a temática do pensamento social brasileiro. Fortemente explorado tem sido seus embates com Florestan Fernandes e Costa Pinto (MATOS, 1996; MAIO, 1997; BARIANI, 2012; HECKSHER, 2004; MARTINS, 2008).

8 Para mais informações sobre sua atuação parlamentar de Guerreiro Ramos, consultar Azevedo e Albernaz (2013) e o pioneiro estudo de autoria de seu ex-aluno Wilson Pizza Jr. (1997). 
mentalidades de seus membros, ele recorreu aos incipientes estudos a respeito do fenômeno das organizações formais e as implicações éticas e morais deste para a vida humana individual e associada, para defender, ante a constatação de a sociedade contemporânea ter-se transformado em uma "sociedade de organizações", a consciência crítica dos sujeitos quanto aos pressupostos inerentes a toda forma de organização, particularmente àquelas que requerem a inconteste servidão humana a seus propósitos.

Foi, portanto, no contexto de suas divergências político-partidárias e a partir de uma visão negativa a respeito das organizações formais que o autor, inspirado na distinção entre atitude natural e atitude crítica encontrada na fenomenologia de Edmund Husserl, definiu, em 1963, a redução sociológica como atitude parentética, ou seja, com um hábito (ou capacidade psicológica) a ser incorporado pelas pessoas em geral (o sociólogo incluso) e que as habilitaria a resistir às mazelas que as organizações formais acarretam ao comportamento e à psicologia humana. Na edição de A redução sociológica de 1965, esse segundo sentido já foi apresentado de maneira mais depurada do contexto que o originou, passando a ser expresso como "adestramento cultural do indivíduo, que o habilita a transcender, no limite do possível, os condicionamentos circunstanciais que conspiram contra sua livre expressão" (GUERREIRO RAMOS, 1965, p. 9).

O terceiro sentido da redução sociológica também é proveniente dos embates do autor e de sua vida militante, mais especificamente da luta contra o racismo e a ideia de raça subjacente à ciência social da época. Nesse sentido, sua origem africana e engajamento no Teatro Experimental do Negro (TEN) fundado por Abdias Nascimento tiveram importância fundamental. Diante da constatação da impropriedade com que o problema das relações raciais vinha sendo tratado no Brasil, ele se verteu à atividade de revisão das ciências sociais no Brasil para compreender a alienação estética que acometia o negro na sociedade brasileira. Desse esforço resultaram os livros O processo da sociologia no Brasil (GUERREIRO RAMOS, 1953), O problema do negro na Sociologia Brasileira (GUERREIRO RAMOS, 1954a) e O negro desde dentro (GUERREIRO RAMOS, 1954b), nos quais denuncia não somente o caráter ideológico dos pressupostos sobre os quais as ciências sociais foram erigidas, mas também a introjeção, pelo homem e mulher negros, de uma "patologia social do 'branco' brasileiro", a saber, a desvalorização social e estética do negro, patologia que os próprios sociólogos e antropólogos estudiosos da condição do negro no Brasil colaboravam em disseminar e fundamentar cientificamente. Em O problema do negro na sociologia brasileira (GUERREIRO RAMOS, 1954a, p. 39), por exemplo, ele afirmou que o negro brasileiro vinha sendo estudado "a partir de categorias e valores induzidos predominantemente da realidade europeia. E assim, do ponto de vista da atitude ou da ótica, os autores nacionais não se distinguem dos estrangeiros, no campo em apreço". Uma coisa, dizia ele em outro momento, é o "negro-tema", o negro como objeto científico, como "coisa examinada, olhada, vista, ora, como ser munificado, ora como traço curioso, ou de qualquer modo como um risco, um traço da realidade nacional que chama a atenção", outra coisa é o "negrovida", esse ser "que não se deixa imobilizar, [que] é despistador, proteico, multiforme, do qual, na verdade, não se pode dar versão definitiva, pois é hoje o que não era ontem e será amanhã o que não é hoje" (GUERREIRO RAMOS, 1957, p. 171). Ou seja, acometidos da cegueira ideológica provocada pela ciência social acriticamente importada e propagada, os cientistas sociais de então, ao converterem o negro em objeto da ciência, melhor dizendo, em um fato científico instruído por valores europeus, por isso mesmo seduzidos pelo sortilégio da cor, deixaram de atentar para o fundamental: a dialética existencial da negritude 9 .

Em verdade, essa percepção do caráter ideológico da sociologia acadêmica brasileira realizada à luz do problema do negro, ou melhor, à luz de sua própria condição de niger sum, transformou-se em denúncia e vinha sendo feita por ele já desde o final da década de 1940. Tal percepção, quando ampliada para a analítica das ciências sociais em geral, o levou à seguinte conclusão:

9 Muryatan Santana Barbosa (2006) faz análise muito interessante dessa questão em seu texto Guerreiro Ramos: o personalismo negro, que somada à análise de Edison Bariani (2008) em Niger sum: Guerreiro Ramos, o "problema" do negro e a sociologia do preconceito e a de Joel Rufino dos Santos (1995) em O negro como lugar, proporcionam a exata medida da visão daquele sociólogo sobre a questão. 
As Ciências Sociais, na forma que assumiram nos meios acadêmicos oficiais, são, em grande parte, uma ideologia dessa dominação, na medida em que os seus enunciados gerais estão afetados do que se poderia chamar de ilusão etnocêntrica ou ptolomaica e, ainda, na medida em que dificultam a compreensão global do processo histórico-social e distraem a atenção dos estudiosos para aspectos fragmentários desse processo (GUERREIRO RAMOS, 1965, p. 159).

O aspecto positivo da questão estava no fato de o contexto mundial da época ser, segundo a sua avaliação, propício para uma tarefa revisionista das ciências sociais, de modo que se pudesse construir uma teoria social atualizada às novas exigências humanas, nacionais e mundiais. A fim de que tal revisão pudesse ser concretizada, era fundamental a contribuição da intelligentzia de países periféricos para depurar o teor etnocêntrico e ideológico de tal teoria. Foi nesses termos que Guerreiro Ramos visualizou a redução sociológica (iii) como uma proposta de "superação da sociologia nos termos institucionais e universitários" de sua época (GUERREIRO RAMOS, 1965, p. 16).

\section{II}

Mas apesar do esclarecimento conceitual levado a efeito pelo autor em 1965, o fato é que mesmo a segunda edição de $A$ redução sociológica não foi muito elucidativa, sobretudo em termos dos desdobramentos teóricos que a noção de redução sociológica trazia em potência para sua trajetória intelectual, uma vez que, devido à cassação de seus direitos políticos em 1964, seu destino era dado como incerto. Somente mais tarde, em 1981, quando da publicação de seu último livro em vida, A nova ciência das organizações: uma reconceituação da riqueza das nações, publicado concomitantemente em inglês pela University of Toronto e em português pela Fundação Getulio Vargas, é que se teria melhor elucidação desses desdobramentos, pois, nele, Guerreiro Ramos apresentaria o seu percurso intelectual, à luz do triplo sentido da redução, desde 1951 até aquela data. De acordo com a sua explicação, ao primeiro sentido do termo atrelaram-se, principalmente, seus livros de 1957 e 1958 (Introdução crítica à sociologia brasileira e A Redução Sociológica); ao segundo, Mito e Verdade da Revolução Brasileira (1963) e Models of man and administrative theory (1972); e, ao terceiro, Situação atual da sociologia (1965 - anexo de A redução sociológica), Administração e Estratégia do desenvolvimento (1966), Modernization: towards a possibility model (1970) e a própria obra A Nova Ciência das Organizações (1981).

Como se observa, a teoria da delimitação dos sistemas sociais e a paraeconomia são devedoras diretas da redução sociológica, em que pese o fato de o livro A nova ciência das organizações (1981) ter sido pensado e escrito em consonância com o status social da realidade norte-americana, realidade que, diga-se de passagem, muito cedo atingiu o cume do padrão de vida da sociedade moderna, situando-se, exatamente, como a principal representante da modernidade, em termos de abastança e de problemas sociais e ambientais crônicos ${ }^{10}$. A articulação sistematizada dessa teoria veio a público pela primeira vez em seu artigo Theory of social systems delimitation: a preliminary statement (GUERREIRO RAMOS, 1976), para depois aparecer

\footnotetext{
${ }^{10}$ É fato que o livro é desconhecido e ignorado pela grande maioria dos sociólogos e cientistas sociais brasileiros. As razões para isso têm menos a ver com a formação em si de nossos cientistas sociais do que com o processo deliberado de esquecimento a que suas obras foram impostas. Lúcia Lippi Oliveira (1995, p. 9), em seu importante livro sobre o pensamento e a trajetória intelectual de Guerreiro Ramos, diz: "[Guerreiro Ramos] reagiu aos cânones da institucionalização das ciências sociais no Brasil e talvez por isso mesmo tenha sido esquecido, marginalizado, excluído do panteão dos cientistas socais brasileiros". Nessa mesma linha explicativa seguem Bariani (2011) e Maia (2012). Para o primeiro, o fato de Guerreiro Ramos ter sido "uma espécie de consciência incômoda da sociologia brasileira", custou-lhe o prestígio e o reconhecimento intelectual que tanto esperava de seus pares e compatriotas; para o segundo, embora ele tenha vivido um período (metade dos anos 1950 até a metade dos anos 1960) de grande reconhecimento de suas ideias, experienciou o "ostracismo intelectual a partir de 1964", partilhando do descrédito de que foram alvos os principais integrantes do Iseb, a partir de críticas orquestradas por intelectuais ligados à USP. Bem, o certo é que, no Brasil, em matéria de projeto de sociologia ou de tradição sociológica, logrou maior sucesso acadêmico aquele que Guerreiro Ramos tanto criticava.
} 
em sua integralidade no livro de 1981, que foi apresentado pelo autor como a consolidação das bases conceituais do terceiro sentido básico que ele houvera atribuído ao termo redução sociológica.

É interessante ressaltar que, em 1965, tratava-se, principalmente, da necessidade de "superação da Sociologia", ao passo que, em 1981, o autor decidiu ampliar as consequências de suas críticas, uma vez que agora visava a "superação da ciência social" enquanto tal e, por conseguinte, a própria superação da teoria das organizações, desde uma crítica fundada nos alicerces epistemológicos que lhes davam fundamentos (GUERREIRO RAMOS, 1981, p. XVI). Mas, como dissemos, a manifestação da necessidade desse processo revisionista data do início dos anos 1950, quando então o autor já denunciava a dominação colonialistaideológica implícita nos pressupostos da ciência social moderna e seus reflexos na postura dos sociólogos brasileiros. Contudo, sua crítica não vislumbrava passar em revista a epistemologia inerente às ciências sociais, especificamente no que se refere à acepção de racionalidade ali articulada, tal como chegaria a concluir no seu último livro: "a raiz do caráter enganoso da ciência social convencional está no conceito de racionalidade que a permeia" (GUERREIRO RAMOS, 1981, p. 194).

A pergunta que emerge, então, é a seguinte: o que vem a ser a razão, para Guerreiro Ramos, especificamente?

\section{III}

Devemos começar com uma constatação: o livro A nova ciência das organizações está inserido em um espaço conceptual complexo, manifestadamente filosófico, teológico, psicológico, sociológico, econômico e político. Tal fato, porém, não nos impede de afirmar que o mesmo é claramente reflexo de um humanismo resultante de uma linha de pensamento filosófica que perpassa a junção do pensamento greco-judaicocristão, do existencialismo e do personalismo, mas que passou por um processo paulatino de revisão, quer dizer, de secularização do pensamento do autor, em função de sua própria trajetória pessoal e intelectual ${ }^{11}$.

Em linhas gerais, esse humanismo abriga uma concepção de homem que não o define enquanto um ser essencial, predeterminado, mas como um dever ser relativo à potência de humanidade que nele subsiste e aspira à realização e incessante atualização. Nesse sentido, o humanismo guerreiriano admite dimensões humanas múltiplas, que podemos, com o auxílio da antropologia filosófica de Lima Vaz (1992 e 2001) ${ }^{12}$, caracterizá-las da seguinte maneira:

a) como corpo e experiência corpórea própria a cada um, vivenciados como realidade do mundo interior e do mundo exterior do qual o sujeito participa, e que, como resposta da relação tensionada dessa realidade entre mundos, anima e dirige intencionalmente o corpo enquanto um instrumento de sua expressão, ação e intervenção nesses dois mundos;

b) como estrutura psíquica, experiência psíquica e personalidade, enquanto consciência (Eu, self) que se forma, de um lado, pelo exercício da mediação entre o mundo interior e o mundo exterior, entre o psíquico e o somático, fruto da condição humana de ser-do-mundo, quer dizer, de achar-se o ente humano na convivência com outros entes, humanos e não humanos, que formam, para ele, o espaço circunstante físico, histórico, cultural e social, e que lhe condicionam o ser-no-mundo, o constituir-se tal como é e deve ser no âmbito em que lhe é dado estar, e, por outro lado, pela também mediação operada no seio da tensão experimentada pelo Eu (self) relativamente à experiência da interioridade absoluta que a relação entre o psíquico e o espírito revelam; e, por fim,

\footnotetext{
${ }^{11}$ Para uma visão mais detida desse humanismo de Guerreiro Ramos, consultar, também de nossa autoria, Alberto Guerreiro Ramos's anthropological approach to the social sciences: the parenthetical man (AZEVEDO e ALBERNAZ, 2006a) ou $A$ antropologia do Guerreiro: a história do conceito de Homem Parentético (AZEVEDO e ALBERNAZ, 2006b).

${ }^{12}$ Sobre a antropologia filosófica de Lima Vaz, consultar Ferreira (2009).
} 
c) como espírito e intelecto (pnêuma, nôus, lógos, synesis), quer dizer, como abertura ao Ser, ao Absoluto, ao Divino, que a experiência da transcendência possibilita.

Não nos restam dúvidas que essa concepção multidimensional humana de Guerreiro Ramos lhe era fundamental, estando presente não apenas em seus escritos, mas em sua própria intervenção na realidade, fato pouco perceptivo, caso se tenha em conta apenas textos como A nova ciência das organizações, pois o mesmo foi escrito com pretensões exclusivamente teóricas, embora com enormes finalidades práticas (GUERREIRO RAMOS, 1982). Em nosso entendimento, sua atuação junto ao Teatro Experimental do Negro, por exemplo, foi toda ela perpassada por essa concepção de humanismo, ou seja, contemplou desde a assunção da negritude - o niger sum fundamental ${ }^{13}$ - até a exclamação do universal transcendente que se encontra simbolizado na arte, na cultura, na beleza, na religião etc. dos negros brasileiros. Porém, o livro de 1981, apesar de não abordar o corpo como substância material e fundamental do sujeito, componente formador do Eu intencional, que o usa como instrumento de sua expressão, de seu aparecer para os outros, é o texto em que o autor mais aprofunda, de maneira já secularizada, como dissemos, a análise das dimensões psíquica e transcendental de seu humanismo, delas retirando fundamentos para uma crítica árdua tanto à concepção de natureza humana quanto a concepção de vida humana associada que vieram a ser instituídas pela ciência social moderna.

A nova ciência... parte de uma concepção de razão distinta daquela que foi acolhida e sistematicamente articulada pela ciência social dominante. Iniciar sua análise por uma história crítica do conceito de razão era, para o sociólogo, um imperativo, porque, por um lado, a razão, normativa por essência, é o que "prescreve como os seres humanos deveriam ordenar sua vida pessoal e social" e, por outro, porque se tratava de "um conceito básico de qualquer ciência da sociedade e das organizações" (GUERREIRO RAMOS, 1981, p. 23, grifo nosso). Nesse sentido, a crítica à ciência social instituída, e que seria levada a efeito pelo autor, não poderia ser adequadamente realizada, caso não se atentasse às implicações desastrosas, para vida individual, a vida associada, a natureza, e para a própria ciência social e teoria das organizações, da concepção de razão que a mesma houvera acolhido, sistematizado e propagado.

Nessa linha, a primeira coisa a ser dita é que o pressuposto inicial do autor é que a razão é um atributo eminentemente humano. Nesse sentido, Guerreiro Ramos segue de perto a definição aristotélica sustentada, por exemplo, em De Anima ${ }^{14}$, ao mesmo tempo em que - e esta é a segunda ressalva a ser feita - assume

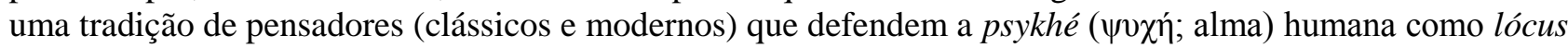
da razão (logos [linguagem] e nôus [intelecto, espírito]) e a ela conferem importante papel na relação de transcendência humana e na própria potencialidade de emancipação. Assim, no campo do conhecimento, a razão possibilita a experiência noética (noêsis) da Verdade; no campo da ética, a experiência do Bem; e, no campo da crença, a experiência do Uno ou do Absoluto. Porque é motor (pnêuma), é ato (enérgeia) em direção ao Ser, ao Fundamento, ao Divino, a razão enquanto nôus torna possível a experiência da transcendência (anábasis) como experiência de participação humana no Ser, no Fundamento, no Divino. Vale lembrar que Aristóteles atribuía ao nôus "tanto a capacidade humana de questionamento cognoscente acerca do fundamento, como o próprio fundamento do ser, que é experienciado como o motor orientador das questões" (VOEGELIN, 2008, p. 6).

Cremos que foi devido a essa característica que Guerreiro Ramos compreendia a razão como "força ativa da psique humana que habilita o indivíduo a distinguir entre o bem e o mal, entre o conhecimento falso e o verdadeiro e, assim, a ordenar sua vida pessoal e social" (GUERREIRO RAMOS, 1981, p. 2-3, grifo nosso). É força ativa, porque é inquietação, é desejo de conhecer, é espírito. É ordenação, porque o conhecimento e a

\footnotetext{
${ }^{13}$ Tal ato consistiria em afirmar: "Sou negro, identifico como meu o corpo em que o meu eu está inserido, atribuo à sua cor a suscetibilidade de ser valorizada esteticamente e considero a minha condição étnica como um dos suportes do meu orgulho pessoal" (GUERREIRO RAMOS, 1954a, grifo do autor).

${ }^{14}$ Temos ciência que, na filosofia, a questão é por demais controversa. Aqui, estamos seguindo a interpretação de Marco Zingano (1998) em seu Razão e sensação em Aristóteles - um ensaio sobre De Anima III 4-5, onde o autor observa que, para Aristóteles, a capacidade eminentemente humana se define pela posse da linguagem e de intelecto, ou seja, de lógos e de nôus, respectivamente.
} 
experiência noética da ordem dirigem o homem a uma ativa participação na vida política ${ }^{15}$. Além disso, dado que a expressão e a inteligibilidade do experienciado pelo nôus, ou seja, do noetón, está a cargo da própria razão na qualidade de logos, fica, dessa forma, estabelecida a relação entre o espírito (nôus) e a palavra (lógos), com especial destaque para o papel deste na inteligibilidade do espírito e no próprio "debate racional" constitutivo da vida política humana (GUERREIRO RAMOS, 1981, p. 27, grifo nosso).

Para fins de melhor compreensão dessa questão, é importante que se esclareça, ainda que de maneira sintética, o papel que a tradição filosófica reservou ao nôus e ao lógos na razão. Embora incida sobre o nôus e o lógos grande polissemia, é possível concentrar essas diferenças em: nôus (a) como pensamento imediato (intuição intelectual) voltado para a apreensão dos indivisíveis, dos princípios não demonstráveis e (b) em sua dimensão mística, sinalizando um encontro com o divino ou de unificação com o Uno, pois o nôus seria a mais divina das realidades; lógos (a) como linguagem, (b) discurso e (c) pensamento proposicional. Na interpretação que lhe conferem Lloyd (1970) e Marcondes (1989), os gregos teriam reservado uma posição secundária ao pensamento discursivo (lógos) frente ao pensamento não-discursivo (nôus), exatamente em razão da relação que estabeleceram entre um e outro. O lógos apenas pode realizar aquilo que o nôu lhe possibilita, a saber, a formulação de um pensamento em enunciado ou proposição. Como disse Marcondes (1989, p. 7), “... a importância e o privilégio atribuídos aos pensamento não-discursivo explicam, em grande parte, o lugar secundário atribuído à linguagem e ao discurso no pensamento clássico".

Foi a clareza desse duplo papel exercido pela razão (nôus e logos) que não permitiu a Guerreiro Ramos conferir ao logos um estatuto superior ao nôus, como, por exemplo, procedeu J. Habermas (1984, 1987), dado que, distintamente do nôus, o logos enquanto linguagem e discurso está também vinculado ao plano sensível, melhor dizendo, ao plano da mediação social, por conseguinte às convenções sociais. Isso implica em assumir que o discurso proferido pode não corresponder àquela afecção psíquica efetuada pelo nôus, especialmente em uma sociedade como a nossa, onde, segundo Guerreiro Ramos (1981), embora no senso comum ainda reste elementos primários das experiências noéticas dos indivíduos ao longo da história, a linguagem e os símbolos e signos modernos que o cidadão comum tem à sua disposição para expressá-las estão fortemente influenciados por uma "psicologia da comunicação instrumental", vítimas graves que os mesmos têm sido das artimanhas da "política cognitiva". ${ }^{16}$

Nesses termos é que se deve entender a força ordenadora da vida pessoal e social que Guerreiro Ramos atribui à razão, tal como se depreende na seguinte passagem: "pelo exercício da razão, e vivendo de acordo com os imperativos éticos dessa razão, o homem transcende a condição de um ser puramente natural e socialmente determinado, e se transforma num ator político" (GUERREIRO RAMOS, 1981, p. 28). É questionável a opinião que vê nessa acepção de razão assumida por Guerreiro Ramos desconsideração da "racionalidade prática" (ANDREWS, 2000) ou ruptura entre o pensar e o agir (FARIA, 2009). Na acepção guerreiriana, que segue de perto a aristotélica, a razão não pode deixar de ser compreendida como partícipe do plano da vida prática. O homem age secundum rationem e cum ratione, age conforme a razão e com razão, ou age com consciência e consciente da lei e dos princípios (cf. ZINGANO, 2009, p. 363-391). Ademais, a razão pode ser dita normativa porque a própria prudência (phrônesis), que opera no interior da virtude moral do indivíduo e desdobra-se em suas ações cotidianas, é, também, uma virtude intelectual (cf. ZINGANO, 2009, p. 499).

Devido às circunstâncias históricas da modernidade, onde "o conceito de razão foi escamoteado por funcionalistas de várias convicções", o que correspondeu ao que o autor denominou de processo de

\footnotetext{
${ }^{15}$ Eric Voegelin foi, certamente, para Guerreiro Ramos, quem, à sua época, melhor conseguia expressar essa característica da razão. Particularmente sobre a compreensão da razão por Voegelin (2002), consultar seu clássico livro Anamnesis.

${ }^{16}$ Política cognitiva "consiste no uso consciente ou inconsciente de uma linguagem distorcida, cuja finalidade é levar as pessoas a interpretarem a realidade em termos adequados aos interesses dos agentes diretos e/ou indiretos de tal distorção" (GUERREIRO RAMOS, 1981, p. 87). Os articuladores conscientes dessa política são designados por Guerreiro Ramos como "agentes da política cognitiva", estando os "mais conscientes deles" engajados em "atividades de comunicação e publicidade", e têm como propósito "influenciar a interpretação que o povo dá à realidade" (GUERREIRO RAMOS, 1981, p. 91).
} 
transvaloração da razão (transvaluation of reason), ou seja, a distorção proposital do conceito de razão com vistas a legitimar um arranjo social "exclusivamente em bases utilitárias" - a sociedade centrada no mercado (GUERREIRO RAMOS, 1981, p. 3, grifo nosso), e para evitar mal-entendidos interpretativos a respeito da peculiaridade de sua acepção do termo razão, Guerreiro Ramos optou por uma adjetivação da razão, designando-a de razão substantiva (GUERREIRO RAMOS, 1981, p. 27).

Não há pioneirismo nessa atitude do autor, pois aqui ele segue (e o faz admitindo) os mesmos passos de Max Weber, Karl Mannheim, Eric Voegelin e Habermas, que cientes do processo de transvaloração da razão, adotaram, respectivamente, os termos razão substantiva, razão substancial, razão noética e razão comunicativa para se contraporem à concepção distorcida da razão que havia sido acolhida tanto nos meios intelectuais quanto no plano da vida ordinária dos indivíduos. Assim procederam para viabilizar suas análises da realidade social e o exame das teorias sociais de suas épocas. Na interpretação de Guerreiro Ramos, por exemplo, haveria, de um lado, uma concepção ainda atrelada ao significado clássico do termo e, de outro, aquela concepção escamoteada da razão e que a partir de Hobbes começou a ser articulada em termos de teoria social e política: Weber a denominou de racionalidade formal e instrumental, Mannheim de racionalidade funcional, Voegelin de racionalidade pragmática e Habermas de racionalidade instrumental. Guerreiro Ramos adotou a terminologia weberiana de racionalidade substantiva e racionalidade instrumental (formal), embora seja perceptível sua afinidade ao modo como Voegelin interpretou a racionalidade noética e tratou de articulá-la em termos de uma nova teoria da ciência política (VOEGELIN, 1982). Aliás, é interessante destacar que o próprio título de seu livro - A nova ciência das organizações - é uma espécie de rendimento de homenagem a Voegelin, que publicou A nova ciência política em 1952. Além disso, Guerreiro Ramos tinha admiração pelo modo como Eric Voegelin (melhor que Max Weber e Karl Mannheim) procurou sistematizar a concepção clássica de razão. Quando, em meados dos anos 1970, mais exatamente em 1973, tomou conhecimento do texto Reason: the classic experience, de Voegelin, nosso sociólogo tratou de lhe escrever para sinalizar suas afinidades de interesses e descobertas nos estudos sobre a razão. Em uma das primeiras cartas que trocaram, Guerreiro Ramos lhe enviou uma cópia de seu Models of man and administrative theory, publicado em 1972, e do rascunho estrutural do livro que mais tarde seria intitulado de A nova ciência das organizações. O título no rascunho original, porém, era The paranthetical man. Em 1974/75, a convite de Guerreiro Ramos, Voegelin esteve na USC para ministrar um seminário sobre Teoria Política.

Como dito, Guerreiro Ramos acusa Thomas Hobbes de ter sido o precursor do proposital esforço intelectual para ressignificação da razão e do papel que a mesma possuía na condução da vida humana individual e pessoal. Para os teóricos posteriores ao escritor inglês esvaneceu-se a possibilidade de a razão substantiva servir como papel normativo no domínio na construção teórica e na vida humana associada. Assim, a razão deixava de ser aquela "força ativa na psique humana" para se tornar, em Hobbes e a partir dele, uma espécie de "capacidade" adquirida pelo "esforço" pessoal que "habilita" o indivíduo a "fazer o "cálculo utilitário de consequências"” (GUERREIRO RAMOS, 1981, p. 3), ou seja, a razão já não é definida em termos de nôus ou mesmo de lógos. Essa interpretação seria a responsável por disseminar e instituir uma visão sociomórfica do homem na ciência política e, posteriormente, na sociologia, mas seus efeitos operacionais maiores se fariam sentir na teoria das organizações.

Em suma, essa transvaloração da razão trouxe diversas implicações, entre as quais: (a) rebaixou a atividade racional humana ao desconsiderar o papel do nôus e do logos (e mesmo da prhônesis) na razão; (b) possibilitou que a razão pudesse ser articulada não mais a partir de sua capacidade de possibilitar a transcendência, mas como um elemento de caráter exclusivamente imanente, o que (c) abriu ensejo para que a mesma fosse redefinida a partir dos aspectos mais operativos no mundo, culminando na acepção exclusiva de razão instrumental ou formal; (d) implicou, por fim, no expurgo da razão da psykhé (ou seja, perda definitiva de seu caráter antropocêntrico) e sua (e) recolocação no plano das relações sociais, nos sistemas sociais e na história; disso resultou (f) uma concepção de natureza humana definida a partir da dimensão sociocomportamental humana.

Além da transvaloração da razão identificada pelo autor, ele também constatou ter havido uma transvaloração do social (transvaluation of social), que, em termos sintéticos, pode ser expressa da seguinte 
forma: primeiramente, ocorreu a transformação do homem - antes considerado como sujeito portador de razão no sentido substantivo - em um ser puramente social; em seguida, a vida social foi esquematizada em uma tríade de relações, a saber, econômicas, de produção e de consumo; o próximo passo foi a libertação da economia - anteriormente um enclave delimitado ao âmbito do lar (oikos) - da regulação política e ética, esta substituída pela justificação do interesse individual imediato; e por fim, a fé na autorregulação do mercado se consolidava, haja vista ter a própria sociedade se tornado um mercado amplificado, o que fez da ordem social não mais um espaço de atuação política de um ser racional, mas um mero espaço constituído pelo somatório dos cálculos individuais. Em outras palavras, somada à transvaloração da razão, a transvaloração do social trouxe como consequência a ascensão do mercado à qualidade de dimensão central e ordenadora, tanto da ciência social como da vida humana em geral na sociedade ocidental moderna.

É nesse contexto que Guerreiro Ramos percebeu e acusou a vinculação da ciência social contemporânea, incluindo a teoria das organizações, com uma determinada época histórica, esta fortemente marcada pela emergência e consolidação do mercado como mecanismo regulador da conduta social e individual. Nesse sentido, denuncia: "a ciência social moderna foi articulada com o propósito de liberar o mercado das peias que, através da história da humanidade e até o advento da revolução comercial e industrial, o mantiveram dentro de limites definidos" (GUERREIRO RAMOS, 1981, p. 22); e adverte: o preço que se tem pago pela ascensão da sociedade centrada no mercado tem sido alto demais, em termos da pessoa humana, da vida coletiva e da própria natureza, por isso a urgência de sua revisão.

Para nosso sociólogo, recuperar o sentido de razão noética ou substantiva implicava em retornar a razão à psique humana e, assim, reforçar seu papel normativo na ordenação da vida pessoal e social. Esse recurso à razão substantiva justificaria torná-la o conceito básico de uma ciência verdadeira da sociedade e das organizações. Todo o desenrolar dessa concepção de antropológica de Guerreiro Ramos o leitor encontrará em seu último livro publicado em vida.

\section{Referências}

ANDREWS, C. W. Revisiting Guerreiro Ramos' The new Science of organizations through Habermasian lenses: a critical tribute. Administrative Theory \& Praxis, v. 22, n. 2, p. 246-272, 2000.

AZEVEDO, A.; ALBERNAZ, R. O. Guerreiro Ramos's anthropological approach to the social sciences: the parenthetical man. Administrative Theory \& Praxis, v. 28, n. 4, p. 501-521, 2006a.

AZEVEDO, A.; ALBERNAZ, R. O. A antropologia do Guerreiro: a história do conceito de Homem Parentético. Cad. EBAPE.BR, v. 4, n. 3, p. 1-19, 2006 b.

AZEVEDO, A.; ALBERNAZ, R. O. A redução sociológica em status nascendi: os estudos literários de Guerreiro Ramos publicados na revista Cultura Política. Organizações \& Sociedade, v. 17, n. 52, p. 47-68, jan./mar. 2010.

AZEVEDO, A.; ALBERNAZ, R. O. Alberto Guerreiro Ramos: deputado guanabarense. In: GURGEL, C.; MARTINS, P. E. M. Estado, organização e pensamento social brasileiro. Niterói, RJ: Ed. UFF, 2013. 253-275 p.

BARBOSA, M. S. Guerreiro Ramos: o personalismo negro. Tempo Social, v. 18, n. 2, p. 217-228, 2006.

BARIANI, E. Niger Sum: Guerreiro Ramos, o "problema" do negro e a sociologia do preconceito. Perspectivas, v. 34, p. 193-211, jul./dez. 2008.

BARIANI, E. Guerreiro Ramos e a redenção sociológica: capitalismo e sociologia no Brasil. São Paulo: Ed. Unesp, 2011.

BARIANI, E. Sociologia no Brasil: uma batalha, duas trajetórias (Florestan Fernandes e Guerreiro Ramos). São Paulo: CRV, 2012. 
DIÁRIO DO CONGRESSO NACIONAL - DCN. Seção I, Brasília, 5 set. 1963a. 6215 p.

DIÁRIO DO CONGRESSO NACIONAL - DCN. Seção I, Brasília, 11 set. 1963b. 11-13 p.

DIÁRIO DO CONGRESSO NACIONAL - DCN. Seção I, Brasília, 10 dez. 1963c. 9677-9678 p.

FARIA, J. H. Consciência crítica com ciência idealista: paradoxo da redução sociológica na fenomenologia de Guerreiro Ramos. Cad. EBAPE.BR, v. 7, n. 3, p. 420-446, set. 2009.

FERREIRA, M. S. O conceito de pessoa humana no pensamento de Lima Vaz. 154 f. Dissertação (Mestrado em Filosofia) - Universidade Estadual do Ceará, Fortaleza, 2009.

GUERREIRO RAMOS, A. A revolução coperniana da sociologia. A Manhã, 14 abr. 1946.

GUERREIRO RAMOS, A. O processo da sociologia no Brasil (esquema de uma história de ideias). Rio de Janeiro: Cândido Mendes Júnior, 1953.

GUERREIRO RAMOS, A. O problema do negro na sociologia brasileira. Cadernos de Nosso Tempo, p. 189-220, jan. 1954a.

GUERREIRO RAMOS, A. O negro desde dentro. Revista Forma, n. 3, out. 1954b.

GUERREIRO RAMOS, A. Introdução crítica à sociologia Brasileira. Rio de Janeiro: Andes, 1957.

GUERREIRO RAMOS, A. A redução sociológica: introdução ao estudo da razão sociológica. Rio de Janeiro: Iseb, 1958.

GUERREIRO RAMOS, A. Mito e verdade da revolução brasileira. Rio de Janeiro: Zahar, 1963.

GUERREIRO RAMOS, A. A redução sociológica: introdução ao estudo da razão sociológica. 2. ed. corrig. aum. Rio de Janeiro: Tempo Brasileiro, 1965.

GUERREIRO RAMOS, A. Administração e estratégia do desenvolvimento: elementos de uma sociologia especial da administração. Rio de Janeiro: Ed. FGV, 1966.

GUERREIRO RAMOS, A. Modernization: towards the possibility model. In: BELING, W. A.; TOTTEN, G. O. (Eds.). Developing nations: quest for a model. New York: Van Nostrand Reinhold, 1970.

GUERREIRO RAMOS, A. Models of man and administrative theory. Public Administration Review, v. 32, n. 3, p. 241-246, May/June 1972.

GUERREIRO RAMOS, A. Theory of social systems delimitation, a preliminary statement. Administration \& Society, v. 8, n. 2, p. 249-272, Aug. 1976.

GUERREIRO RAMOS, A. A nova ciência das organizações: uma reconceituação da riqueza das nações. Rio de Janeiro: Ed. FGV, 1981.

GUERREIRO RAMOS, A. Minha dívida a Lord Keynes. Rev. Adm. Pública, v. 16, n. 2, p. 91-95, abr./jun. 1982.

GUERREIRO RAMOS, A. A redução sociológica. 3. ed. Rio de Janeiro: Ed. FGV, 1995.

HABERMAS, J. The theory of communicative action: reason and the rationalization of society (volume 1). Boston: Beacon Press, 1984.

HABERMAS, J. The theory of communicative action: lifeworld and system - a critique of functionalist reason (volume 2). Boston: Beacon Press, 1987. 
HECKSHER, M. H. Guerreiro Ramos: sociólogo da sociologia nacional (um diálogo com Florestan Fernandes). 352 f. Tese (Doutorado em Serviço Social) - Universidade Federal do Rio de Janeiro, Rio de Janeiro, 2004.

LLOYD, A. C. Non-discursive thought: an enigma of Greek philosophy. Proceedings of the Aristotelian Society, v. 70, p. 261-274, 1970.

MAIA, J. M. E. Reputações à brasileira: o caso de Guerreiro Ramos. Sociologia \& Antropologia, v. 2, n. 4, p. 265-291, 2012.

MAIO, M. C. Uma polêmica esquecida: Costa Pinto, Guerreiro Ramos e o tema das relações raciais. Dados, v. 40, n. 1, p. $127-163,1997$.

MARCONDES, D. Nôus vs. Lógos. Cadernos do Departamento de Filosofia da PUC-Rio, v. 1, n. 1, p. 7-14, 1989.

MARTINS, T. G. Florestan Fernandes e Guerreiro Ramos: para além de um debate. 230 f. Tese (Doutorado em Sociologia) - Universidade Estadual de Campinas, Campinas, 2008.

MATOS, B. T. P. Diálogo de surdos: academia e política na trajetória de Florestan Fernandes e Guerreiro Ramos. Caderno Linhas Críticas, n. 3-4, p. 149-171, jul. 1996,

OLIVEIRA, L. L. A sociologia do Guerreiro. Rio de Janeiro: Ed. UFRJ, 1995.

PIZZA Jr., W. Trajetória parlamentar de Alberto Guerreiro Ramos. Rev. Adm. Pública, v. 31, n. 5, p. 24-28, set./out. 1997.

SANTOS, J. R. O negro como lugar. In: GUERREIRO RAMOS, A. A redução sociológica. 3. ed. Rio de Janeiro: Ed. FGV, 1995. 19-29 p.

VAZ, H. L. Antropologia filosófica. São Paulo: Loyola, 1992. v. 2.

VAZ, H. L. Antropologia filosófica. 6. ed. São Paulo: Loyola, 2001. v. 1.

VOEGELIN, E. A nova ciência política. 2. ed. Brasília, DF: Ed. UnB, 1982.

VOEGElIN, E. Anamnesis: On the Theory of History and Politics. Columbia, MO: University of Missouri Press, 2002. (The Collected Works of Eric Voegelin, v. 6).

VOEGELIN, E. A consciência do fundamento. Covilhã: Lusofia, 2008.

ZINGANO, M. Razão e sensação em Aristóteles: um ensaio sobre De Anima III 4-5. Porto Alegre: L\&PM, 1998.

ZINGANO, M. Estudos de ética antiga. 2. ed. São Paulo: Discurso Editorial/Paulus, 2009. 